\title{
Clinical Characteristics of Severe Erosive Esophagitis among Patients with Erosive Esophagitis: A Case-control Study
}

\author{
Tomonori Ida ${ }^{1}$, Masahiko Inamori ${ }^{2}$, Yumi Inoh ${ }^{3}$, Koji Fujita ${ }^{3}$, Jun Hamanaka ${ }^{1}$, \\ Hideyuki Chiba ${ }^{1}$, Akihiko Kusakabe ${ }^{4}$, Taiki Morohashi ${ }^{1}$, Toru Goto ${ }^{1}$ and Shin Maeda ${ }^{5}$
}

\begin{abstract}
Objective The risk factors associated with severe erosive esophagitis are not well defined in Japan. We aimed to evaluate the risk factors associated with the endoscopic severity of esophageal mucosal injury.

Methods Eighty consecutive Japanese patients with severe erosive esophagitis [Los Angeles (LA) classification grade $\mathrm{C}$ or D] who had undergone upper endoscopies in the Gastroenterology Division of Omori Red Cross Hospital between June 2010 and March 2013 were retrospectively analyzed. For each case, a control with mild erosive esophagitis (LA classification grade A or B) who was matched by sex and age was randomly selected during the same period. Among the endoscopic findings, the condition of the gastroesophageal flap valve (GEFV) was graded according to Hill's classification. We identified the risk factors for severe erosive esophagitis using a multivariable logistic regression model.

Results A poor performance status (PS) (odds ratio $[\mathrm{OR}]=17.1201,95 \%$ confidence interval $[\mathrm{CI}]=3.0268$ 140.3121, $\mathrm{p}=0.0008)$ and an abnormal GEFV $(\mathrm{OR}=3.0176,95 \% \mathrm{CI}=1.0589-9.4939, \mathrm{p}=0.0385)$ were risk factors for severe erosive esophagitis, while the presence of open-type gastric mucosal atrophy (GMA) was inversely associated with severe erosive esophagitis $(\mathrm{OR}=0.2772,95 \% \mathrm{CI}=0.1087-0.6675, \mathrm{p}=0.0040)$.

Conclusion Among patients with erosive esophagitis, a poor PS and an abnormal GEFV were associated while GMA was inversely associated with severe erosive esophagitis. Drug therapy alone or in combination with physical therapy may improve the therapeutic effect on severe erosive esophagitis in patients with a poor PS.
\end{abstract}

Key words: severe erosive esophagitis, risk factor, gastroesophageal flap valve

(Intern Med 56: 1293-1300, 2017)

(DOI: 10.2169/internalmedicine.56.8058)

\section{Introduction}

The prevalence of erosive esophagitis in Japan is estimated to be low compared with findings in Western countries, although recent studies have shown that the number of patients with erosive esophagitis has been increasing in Japan (1).

Previous studies reported that the absence of Helicobacter pylori infection, the presence of kyphosis or gibbus in eld- erly subjects and size of a hiatal hernia tend to be associated with an increased risk of erosive esophagitis (2-4). The majority of cases of erosive esophagitis in Japan were of a mild type. However, in general hospitals, we sometimes experience severe cases of erosive esophagitis with episodes of gastrointestinal bleeding.

In the present case-control study, we evaluated Japanese patients with severe erosive esophagitis and defined the risk factors that contribute to its development. Recognition of the predictors of severe erosive esophagitis is clinically and eco-

\footnotetext{
${ }^{1}$ Department of Gastroenterology, Omori Red Cross Hospital, Japan, ${ }^{2}$ Department of Medical Education, Yokohama City University School of Medicine, Japan, ${ }^{3}$ Office of Postgraduate Medical Education, Yokohama City University Hospital, Japan, ${ }^{4}$ Department of General Medicine, Yokohama City University Hospital, Japan and ${ }^{5}$ Department of Gastroenterology, Yokohama City University Hospital, Japan Received for publication July 31, 2016; Accepted for publication October 3, 2016 Correspondence to Dr. Masahiko Inamori, inamorim@med.yokohama-cu.ac.jp
} 
nomically important. In this study, we reviewed the medical records of patients with erosive esophagitis and analyzed the data on their comorbidities, lifestyle habits, medications and endoscopic findings.

\section{Materials and Methods}

\section{Patients}

Eighty consecutive Japanese patients (53 men, 27 women; median age: 74 years; age range: $40-96$ years) with severe erosive esophagitis [Los Angeles (LA) classification grade C or D] who had undergone upper endoscopies in the Gastroenterology Division of Omori Red Cross Hospital between June 2010 and March 2013 were retrospectively analyzed. For each case, a control with mild erosive esophagitis (LA classification grade A or B) who was matched by sex and age was randomly selected from among patients who had undergone endoscopies during the same period and who had no endoscopically observed localized lesions in the upper gastrointestinal tract. The exclusion criteria were an inability to obtain a complete patient profile from the medical records and the refusal of the patient to participate in the study. The patients were also excluded if they had a history of gastric or esophageal surgery and were ineligible for inclusion if they had evident disease or Zollinger-Ellison syndrome or primary esophageal motility disorders, or if they were pregnant or lactating.

\section{Endoscopic diagnosis}

Erosive esophagitis was diagnosed based on the Los Angeles classification (5) and was divided into two categories: mild (grades A and B) and severe (grades C and D). Additionally, the presence of Barrett's epithelium was diagnosed based on the Prague C \& M criteria (6). Under these criteria, Barrett's epithelium is defined as the macroscopic identification of abnormal columnar esophageal epithelium more than $1 \mathrm{~cm}$ in thickness, which is suggestive of a columnarlined distal esophagus, as determined on a standard endoscopy examination with the pull-out technique. The length of Barrett's epithelium is measured in centimeters using the circumferential extent (the $\mathrm{C}$ extent) and the maximum extent (the $\mathrm{M}$ extent) above the gastroesophageal junction, identified as the proximal margin of the gastric mucosal folds.

We also examined the gastroesophageal junction to assess the geometry of the gastroesophageal flap valve (GEFV). The GEFV is formed by the sling musculature of the gastric cardia, which is located in the gastric cardia portion maintaining the acute angle of His (7) and which plays an important role as a gate against retrograde gastric flow (8-11). The GEFV condition was assessed using still images of the retroflex view of the gastric cardia and was graded I through IV according to Hill's classification (Figure) (12). We defined GEFV grades I and II as a normal GEFV and grades III and IV as an abnormal GEFV (13-15). Furthermore, on endoscopy, the gastric mucosal atrophy (GMA) was classified as closed or open type according to the KimuraTakemoto classification (16).

Endoscopic images from these patients were retrieved from the endoscopic filing system (Olympus Medical Systems, Tokyo, Japan). All digital endoscopic images were independently and retrospectively reviewed by two trained endoscopists to investigate the endoscopic findings, including the findings related to GMA, the GEFV, erosive esophagitis, and Barrett's epithelium. If there was any inconsistency in the assessment of the digital endoscopic images, a final diagnosis was decided upon by a joint review of the images.

\section{Patient profiles}

We obtained complete patient information at the time of the initial diagnosis from each patient's medical records, including the age; sex; performance status (PS); the presence or absence of a gibbus; symptoms of heartburn, which was defined as a burning feeling rising from the stomach or the lower part of the chest towards the neck; signs of gastrointestinal bleeding such as hematemesis or tarry stool; body mass index (BMI); current regular drinking habits and current smoking habits; blood parameters, such as hemoglobin $(\mathrm{Hb})$ and $\mathrm{C}$-reactive protein (CRP); the presence of concomitant diseases under medical treatment; and medications. The PS was assessed using the Eastern Cooperative Oncology Group (ECOG) scale of performance status, where PS 0 means normal activity; PS 1 means certain symptoms, but still nearly fully ambulatory; PS 2 means spending $<50 \%$ of daytime in bed; PS 3 means spending $\geq 50 \%$ of daytime in bed; and PS 4 means completely bedridden (17).

\section{Statistical analyses}

The statistical analyses included a chi-squared test with or without Yates' correction or Fisher's exact test to compare percentages and a Mann-Whitney U-test to compare continuous data. Various risk factors were also evaluated simultaneously using multiple logistic regression. The level of significance was defined as $\mathrm{p}<0.05$. All of the statistical analyses were performed using the StatView software program (ver. 5.0) and JMP software program (ver. 11.2; SAS Institute, Cary, USA) and EZR (Saitama Medical Center, Jichi Medical University, Japan) (18).

\section{Ethics}

The study was conducted in accordance with the Declaration of Helsinki. The study protocol was approved by the Ethics Committee of the Omori Red Cross Hospital.

\section{Results}

\section{Clinical characteristics of the patient profiles}

A comparison of the patient profiles between the case group (with severe erosive esophagitis) and the control group (with mild erosive esophagitis) is shown in Table 1. 

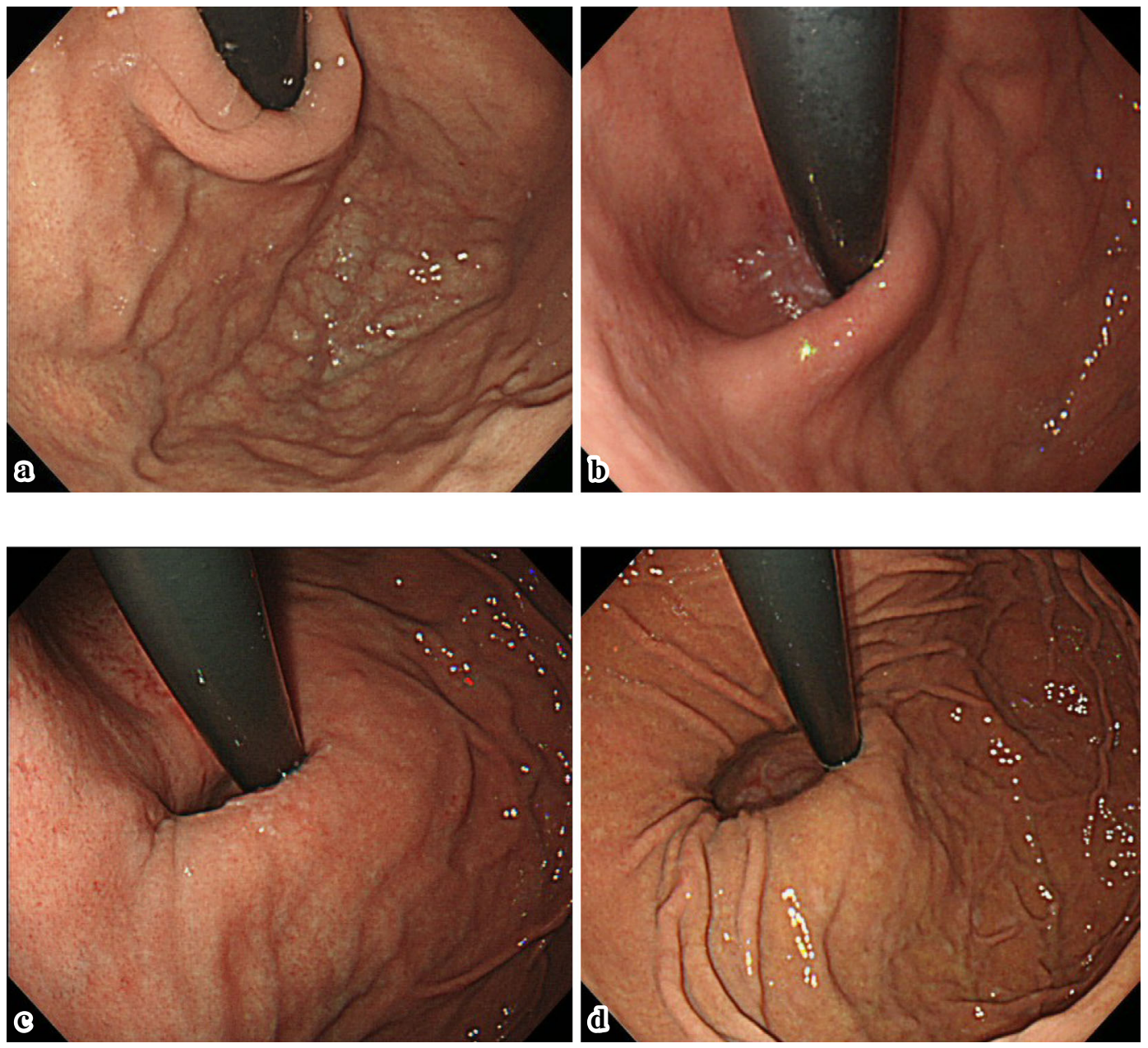

Figure. Retroflexed view of the gastroesophageral flap valve. (a) Grade I. The prominent fold of tissure along the lesser curvature was closely apposed to the endoscope. (b) Grade II. The fold was present but there would be periods of opening and rapid closing around the endoscope. (c) Grade III. The fold was not prominent and the endoscope was not gripped tightly by the ridge. (d) Grade IV. There was no fold and the lumen of the esophagus gaped open, allowing the squamous epithelium to be viewed below.

The subjects were 27 females and 53 males, and the median (range) age was 74.0 (40.0-96.0) years in both the case and control groups. The results of a univariate analysis of the clinical factors showed that there were significantly more patients with a poor general condition, or PS 3 or $4(\mathrm{p}<$ $0.0001)$; having a gibbus $(\mathrm{p}=0.0375)$; and having a low BMI $(p=0.0191)$ in the case group than in the control group. There was no significant difference in the prevalence of heartburn symptoms between the two groups, but patients with signs of gastrointestinal bleeding were predominant in the case group. The prevalence of current regular drinking and current smoking habits was not significantly different between the two groups. Regarding the blood parameters, anemia and a mounting inflammatory reaction were significantly more frequent in the case group than in the control group.

\section{Prevalence of comorbidities}

The prevalence of comorbidities in patients with severe erosive esophagitis and the control group is shown in Ta- ble 2. There was no difference in the prevalence of comorbidities between the two groups, other than for dementia, which was more frequently present in the case group than in the control group.

\section{Prevalence of medication-associated risk factors}

The findings regarding the daily use of medicine are shown in Table 3. Only proton pump inhibitor (PPI) use was predominant in the case group, whereas other medications did not significantly differ in use between the groups. Patients using PPIs were found in both groups. PPI treatment might change the grade of esophagitis from severe to mild. Patients with severe esophagitis treated by PPIs were considered extremely intractable cases among those with erosive esophagitis.

\section{Endoscopic findings}

The endoscopic findings are shown in Table 4. Esophageal complications were observed only in the severe group: $15(18.8 \%)$ had bleeding, $7(8.8 \%)$ had stenosis, and 27 
Table 1. Clinical Characteristics of the Patients with Severe EE $(n=80)$ and with Mild EE as the Control $(n=80)$.

\begin{tabular}{|c|c|c|c|}
\hline & Sever EE $(n=80)$ & Control $(n=80)$ & $\mathrm{p}$ value \\
\hline $\begin{array}{l}\text { Age: median (range) in } \\
\text { years }\end{array}$ & $74.0(40.0-96.0)$ & $74.0(40.0-96.0)$ & 1.0000 \\
\hline Sex: male; n (\%) & $53(66.25)$ & $53(66.25)$ & 1.0000 \\
\hline \multicolumn{4}{|l|}{ PS: n $(\%)$} \\
\hline 0 & $39(48.8)$ & $63(78.8)$ & \\
\hline 1 & 15 (18.8) & $11(13.8)$ & \\
\hline 2 & $5(6.3)$ & $3(3.8)$ & 0.0002 \\
\hline 3 & $11(13.8)$ & 0 & \\
\hline 4 & $10(12.5)$ & $3(3.8)$ & \\
\hline PS 3 or $4: \mathrm{n}(\%)$ & $21(26.3)$ & $3(3.8)$ & $<0.0001$ \\
\hline Gibbus: n (\%) & $19(23.8)$ & $9(11.3)$ & 0.0375 \\
\hline Heartburn symptoms: n (\%) & $42(52.5)$ & $42(52.5)$ & 1.0000 \\
\hline $\begin{array}{l}\text { Gastrointestinal bleeding } \\
\text { signs: } \mathrm{n}(\%)\end{array}$ & $30(37.5)$ & $4(5.0)$ & $<0.0001$ \\
\hline BMI: median (range) & $21.9(14.6-35.5)$ & $23.0(16.4-36.0)$ & 0.0191 \\
\hline Current smoker: $\mathrm{n}(\%)$ & $29(36.3)$ & $20(25.0)$ & 0.1227 \\
\hline $\begin{array}{l}\text { Brinkman index: mean } \\
\text { (range) }\end{array}$ & $301.5(0-2,880)$ & $235(0-1,660)$ & 0.3830 \\
\hline Heavy drinker: n (\%) & $19(23.8)$ & $16(20.0)$ & 0.5662 \\
\hline \multicolumn{4}{|l|}{ Blood examination } \\
\hline $\mathrm{Hb}$ : mean (median) $(\mathrm{g} / \mathrm{dL})$ & $11.7(12.1)$ & $13.2(14.1)$ & 0.0013 \\
\hline $\mathrm{CRP}(\mathrm{mg} / \mathrm{dL})$ & $2.330(0.825)$ & $0.384(0.070)$ & $<0.0001$ \\
\hline
\end{tabular}

BMI: Body mass index

CRP: C-reactive protein

Table 2. Prevalence of Comorbidities in Patients with Severe EE and the Control Group.

\begin{tabular}{lrrr}
\hline Comorbidities & Sever EE $(\mathrm{n}=80)$ & Control $(\mathrm{n}=80)$ & $\mathrm{p}$ value \\
\hline Diabetes: $\mathrm{n}(\%)$ & $18(22.5)$ & $19(23.8)$ & 0.8513 \\
Hypertension: $\mathrm{n}(\%)$ & $28(35.0)$ & $33(41.3)$ & 0.4157 \\
Asthma: $\mathrm{n}(\%)$ & $3(3.8)$ & $2(2.5)$ & 0.6496 \\
Chronic renal failure: $\mathrm{n}(\%)$ & $4(5.0)$ & $4(5.0)$ & 1.0000 \\
Chronic heart failure: $\mathrm{n}(\%)$ & $6(7.5)$ & $7(8.8)$ & 0.7723 \\
Ischemic heart disease: $\mathrm{n}(\%)$ & $5(6.3)$ & $1(1.3)$ & 0.0960 \\
Cerebrovascular disease: $\mathrm{n}(\%)$ & $14(17.5)$ & $12(15.0)$ & 0.6682 \\
Gastroduodenal ulcer: $\mathrm{n}(\%)$ & $16(20.0)$ & $17(21.3)$ & 0.8451 \\
COPD: $\mathrm{n}(\%)$ & $5(6.3)$ & $1(1.3)$ & 0.0960 \\
Neurodegenerative disease: $\mathrm{n}(\%)$ & $6(7.5)$ & $6(7.5)$ & 1.0000 \\
Dementia: $\mathrm{n}(\%)$ & $10(12.5)$ & $2(2.5)$ & 0.0163 \\
Arrhythmia: $\mathrm{n}(\%)$ & $2(2.5)$ & $4(5.0)$ & 0.4053 \\
Depression: $\mathrm{n}(\%)$ & $5(6.3)$ & $8(10.0)$ & 0.3854 \\
Osteoporosis: $\mathrm{n}(\%)$ & $6(7.5)$ & $4(5.0)$ & 0.5136 \\
Liver cirrhosis: $\mathrm{n}(\%)$ & $3(3.8)$ & $1(1.3)$ & 0.3112 \\
\hline COPD: chr
\end{tabular}

COPD: chronic obstructive pulmonary disease

(33.8\%) had an ulcer. The prevalence of Barrett's epithelium was significantly higher in the case group than in the control group $(\mathrm{p}<0.0001)$. A total of $58(72.5 \%)$ patients had no atrophic gastritis (GMA closed type) in the case group, and this proportion was significantly higher $(\mathrm{p}=0.0001)$ than in the control group (34 patients, 42.5\%). In addition, the prevalence of an abnormal GEFV (Hill grade III or IV) was significantly higher in the severe group (71 patients, $88.8 \%$ ) than in the case group (50 patients, $62.5 \% ; \mathrm{p}=0.0001$ ).

\section{Clinical factors associated with severe erosive esophagitis}

The results of the multiple logistic regression analysis of the clinical factors associated with severe erosive esophagitis 
Table 3. Prevalence of Medicational Risk Factor in Patients with Severe EE and the Control Group.

\begin{tabular}{lrrr}
\hline Medications & Sever EE $(\mathrm{n}=80)$ & Control $(\mathrm{n}=80)$ & $\mathrm{p}$ value \\
\hline PPI: $\mathrm{n}(\%)$ & $25(31.3)$ & $14(17.5)$ & 0.0428 \\
NSAIDs: $\mathrm{n}(\%)$ & $14(17.5)$ & $8(10.0)$ & 0.1684 \\
Steroids: $\mathrm{n}(\%)$ & $5(6.3)$ & $1(1.3)$ & 0.0960 \\
Bisphosphonates: $\mathrm{n}(\%)$ & $5(6.3)$ & $4(5.0)$ & 0.7315 \\
Calcium blockers: $\mathrm{n}(\%)$ & $16(20.0)$ & $24(30.0)$ & 0.1441 \\
ACE inhibitors: $\mathrm{n}(\%)$ & $19(23.8)$ & $19(23.8)$ & 1.0000 \\
$\beta$-blockers: $\mathrm{n}(\%)$ & $5(6.3)$ & $2(2.5)$ & 0.2462 \\
Nitrites: $\mathrm{n}(\%)$ & $4(5.0)$ & $3(3.8)$ & 0.6991 \\
Xanthines: $\mathrm{n}(\%)$ & $2(2.5)$ & $0(0)$ & 0.1547 \\
Sulfonylureas: $\mathrm{n}(\%)$ & $7(8.8)$ & $7(8.8)$ & 1.0000 \\
Anti-thrombotic medicines including & $20(25.0)$ & $19(23.8)$ & 0.8539 \\
low-dose aspirin: $\mathrm{n}(\%)$ & $16(20.0)$ & $15(18.8)$ & 0.8415 \\
Cerebral nerve and antipsychotic & & & \\
drugs: $\mathrm{n}(\%)$ & & & \\
\hline
\end{tabular}

PPI: proton pump inhibitor

ACE: angiotensin-converting enzyme

Table 4. Endoscopic Findings

\begin{tabular}{lrrr}
\hline \multicolumn{1}{c}{ Endoscopic findings } & Sever EE $(\mathrm{n}=80)$ & Control $(\mathrm{n}=80)$ & $\mathrm{p}$ value \\
\hline Esophageal complications & & & \\
$\quad$ Bleeding: $\mathrm{n}(\%)$ & $15(18.8)$ & 0 & $<0.0001$ \\
Stenosis: $\mathrm{n}(\%)$ & $7(8.8)$ & 0 & 0.0068 \\
Ulcer: $\mathrm{n}(\%)$ & $27(33.8)$ & 0 & $<0.0001$ \\
& & & \\
GMA open type: $\mathrm{n}(\%)$ & $22(27.5)$ & $46(57.5)$ & 0.0001 \\
& & & \\
Hill's grade: $\mathrm{n}(\%)$ & & & \\
I & $9(11.2)$ & $28(35.0)$ & $<0.0001$ \\
II & $27(33.8)$ & $31(38.8)$ & \\
III & $44(55.0)$ & $19(23.7)$ & \\
IV & $71(88.8)$ & $50(62.5)$ & 0.0001 \\
Hill's grades III and IV: $\mathrm{n}(\%)$ & & & \\
Barrett's epithelium: $\mathrm{n}(\%)$ & $56(70.0)$ & $22(27.5)$ & $<0.0001$ \\
\hline GMA: gastromucosal atrophy & & &
\end{tabular}

are shown in Table 5. After adjustments for clinical factors, a poor PS (odds ratio $[\mathrm{OR}]=17.1201,95 \%$ confidence interval $[\mathrm{CI}]=3.0268-140.3121, \mathrm{p}=0.0008)$ and an abnormal GEFV $(\mathrm{OR}=3.0176,95 \% \mathrm{CI}=1.0589-9.4939, \mathrm{p}=0.0385)$ were found to be risk factors for severe erosive esophagitis, while the presence of open-type GMA was inversely associated with severe erosive esophagitis $(\mathrm{OR}=0.2772,95 \%$ $\mathrm{CI}=0.1087-0.6675, \mathrm{p}=0.0040)$. Signs of gastrointestinal bleeding $(\mathrm{OR}=4.3351,95 \% \mathrm{CI}=1.2074-18.5115, \mathrm{p}=$ $0.0239), \mathrm{CRP}(\mathrm{OR}=1.8122,95 \% \mathrm{CI}=0.3251-0.8621, \mathrm{p}=$ 0.0053 ) and a prevalence of Barrett's epithelium were also significantly associated with severe erosive esophagitis (OR $=9.6271,95 \% \mathrm{CI}=3.9626-25.7395, \mathrm{p}<0.0001)$.

\section{Discussion}

This study examined the presence of severe erosive esophagitis and the risk factors associated with its severity through a retrospective case-control study matched by age and sex. Based on the results of the multivariate analysis, a poor PS and an abnormal GEFV (Hill grade III or IV) showed a strong association with severe erosive esophagitis. In contrast, the presence of open-type GMA was inversely related to severe erosive esophagitis (OR, 0.2772).

Several reasons may explain the finding that a poor PS was related to severe erosive esophagitis. For example, poor PS patients are kept in the supine position for a long time, causing delayed gastric emptying, which may increase the likelihood of gastroesophageal reflux. Previous studies have 
Table 5. Multiple Logistic Regression Analysis Using Parameters with a $p$ value of Less than 0.1 Identified from Univariate Regression Analysis.

\begin{tabular}{lrrr}
\hline \multicolumn{1}{c}{ Clinical factors } & Odds ratio & \multicolumn{1}{c}{$95 \%$ CI } & p value \\
\hline PS 3 and 4 & 17.1201 & $3.0268-140.3121$ & 0.0008 \\
Hill's grades III and IV & 3.0176 & $1.0589-9.4939$ & 0.0385 \\
GMA: open type & 0.2772 & $0.1087-0.6675$ & 0.0040 \\
Gastrointestinal bleeding signs & 4.3351 & $1.2074-18.5115$ & 0.0239 \\
CRP & 1.8122 & $0.3251-0.8621$ & 0.0053 \\
Barrett's epithelium: n (\%) & 9.6271 & $3.9626-25.7395$ & $<0.0001$ \\
Gibbus & 0.2796 & $0.0528-1.2856$ & 0.1027 \\
\hline
\end{tabular}

CI: confidence interval

suggested that the normal cardia is more competent in the supine position than in the upright position, and the progression from a normal lower esophageal sphincter (LES) to one that is completely defective correlates with dysfunction of the GEFV. In poor PS patients with an abnormal GEFV, the protective effect of the LES in the supine position may be impaired. Furthermore, the LES has been shown to be commonly defective in poor PS patients, regardless of body position, and subsequent bipositional reflux, which predominates in the supine position, causes severe esophageal mucosal damage $(19,20)$. Gastric fluid would consequently be able to flow back into the esophagus in the supine position but could not be cleared effectively within a short period, resulting in longer esophageal acid exposure and therefore greater mucosal damage $(19,20)$.

Gastrointestinal bleeding signs, CRP positivity, and Barrett's epithelium were not causes of severe esophagitis but might instead be considered a result. CRP positivity in particular might reflect the inflammation of the esophageal mucosa and/or severe erosive esophagitis coupled with a poor PS, possibly leading to aspiration pneumonia caused by acid reflux. The presence of a gibbus, a low BMI, and comorbid dementia, which were predominant in cases of severe erosive esophagitis in the univariate analysis, might be reflective of a poor PS as well.

Hill's classification is useful as an endoscopic predictor of the severity of esophagitis because of the high reproducibility of the findings. Previous studies have reported a correlation between hiatal hernia and erosive esophagitis. However, the endoscopic diagnosis of a hiatal hernia is poorly reproducible and depends largely on the distension of the stomach. Previous reports have suggested that an abnormal GEFV configuration may serve as an independent factor predicting a poor response to PPI therapy $(21,22)$. The results of our survey showed that PPI use was more frequent in the severe erosive esophagitis group, suggesting the possibility of PPI resistance and that mucosal healing is limited with PPI therapy alone. In addition, Chang et al. demonstrated that the prevalence of acid reflux in the supine position correlated more closely with loosening of the GEFV than the upright position (23). It was speculated that, in the abnormal GEFV group, the gastric contents were able to re- flux more easily in the supine position, with a lower gravity effect, due to attenuation of the collar sling musculature of the flap valve (24). Drug therapy either alone or in combination with physical therapy may improve the therapeutic effect on severe erosive esophagitis in patients with a poor PS. In accordance with the findings of previous reports (24-27), we showed that the presence of GMA was negatively correlated with the severity of erosive esophagitis. This may be due to Helicobacter pylori infection, which prevents erosive esophagitis through the induction of atrophic gastritis and reduced acid secretion (28).

In the present study, lifestyle-related factors, such as smoking, drinking habits, and obesity, were less closely associated with the severity of erosive esophagitis in the multiple logistic regression analysis than other factors. In previous reports (29-39), these parameters were found to be risk factors for erosive esophagitis, but the roles of lifestyle risk factors in erosive esophagitis are still poorly defined and remain controversial (40-44). Thus, lifestyle-related factors might be risk factors for erosive esophagitis (and especially mild erosive esophagitis, such as LA grade A or B) but may not be related to the severity of erosive esophagitis. In addition, even if patients drink or smoke excessively and are obese, their erosive esophagitis may not be severe unless their PS becomes poor. Another reason for the poor relationship between lifestyle profiles and the severity of erosive esophagitis might be that our study did not include superobese patients but did include relatively old patients and patients with a poor PS who did not smoke or drink.

Several limitations associated with the present study warrant mention. First, this was a retrospective study, and there might have been bias in reviewing the findings of the endoscopic photographs. Second, the presence of $H$. pylori was not determined, although the presence of GMA reflects $H$. pylori infection. Therefore, the evaluation of GMA compensates for this limitation to a certain degree. Third, this study was an age-matched case-control study, which might have prevented age from being identified as a significant risk factor, although esophagitis is common in the elderly.

In conclusion, among patients with erosive esophagitis, a poor PS and an abnormal GEFV were associated while GMA was inversely associated with severe erosive esophagi- 
tis. The endoscopic findings regarding the GEFV and GMA as well as the PS are therefore useful for predicting the risk of erosive esophagitis. However, a longitudinal follow-up study in a large cohort may be needed to further evaluate the risk factors and clarify the path to prevention.

The authors state that they have no Conflict of Interest (COI).

\section{References}

1. Fujiwara Y, Arakawa T. Epidemiology and clinical characteristics of GERD in the Japanese population. J Gastroenterol 44: 518-534, 2009.

2. Maekawa T, Kinoshita Y, Okada A, et al. Relationship between severity and symptoms of reflux oesophagitis in elderly patients in Japan. J Gastroenterol Hepatol 13: 927-930, 1998.

3. Furukawa N, Iwakiri R, Koyama T, et al. Proportion of reflux esophagitis in 6010 Japanese adults: prospective evaluation by endoscopy. J Gastroenterol 34: 441-444, 1999.

4. Kusano M, Hashizume K, Ehara Y, et al. Size of hiatus hernia correlates with severity of kyphosis, not with obesity, in elderly Japanese women. J Clin Gastroenterol 42: 345-350, 2008.

5. Lundell LR, Dent J, Bennett JR, et al. Endoscopic assessment of oesophagitis: clinical and functional correlates and further validation of the Los Angeles classification. Gut 45: 172-180, 1999.

6. Sharma P, Dent J, Armstrong D, et al. The development and validation of an endoscopic grading system for Barrett's esophagus: the Prague C \& M criteria. Gastroenterology 131: 1392-1399, 2006.

7. Liebermann-Meffert D, Allgöwer M, Schmid P, Blum AL. Muscular equivalent of the lower esophageal sphincter. Gastroenterology 76: 31-38, 1979.

8. Orlando RC. Overview of the mechanisms of gastroesophageal reflux. Am J Med 111 (Suppl 8A): 174S-177S, 2001.

9. Paterson WG. The normal antireflux mechanism. Chest Surg Clin N Am 11: 473-483, 2001.

10. Mittal RK, Balaban DH. The esophagogastric junction. N Engl J Med 336: 924-932, 1997.

11. Delattre JF, Palot JP, Ducasse A, Flament JB, Hureau J. The crura of the diaphragm and diaphragmatic passage. Applications to gastroesophageal reflux, its investigation and treatment. Anat Clin 7: 271-283, 1985.

12. Hill LD, Kozarek RA, Kraemer SJ, et al. The gastroesophageal flap valve: in vitro and in vivo observations. Gastrointest Endosc 44: 541-547, 1996.

13. Takeuchi R, Kato K, Mizuno S, et al. Abnormal gastroesophageal flap valve is highly associated with endoscopic reflux esophagitis after Helicobacter pylori eradication. Helicobacter 9: 1-8, 2004.

14. Kim GH, Kang DH, Song GA, et al. Gastroesophageal flap valve is associated with gastroesophageal and gastropharyngeal reflux. J Gastroenterol 41: 654-661, 2006.

15. Kim GH, Song GA, Kim TO, et al. Endoscopic grading of gastroesophageal flap valve and atrophic gastritis is helpful to predict gastroesophageal reflux. J Gastroenterol Hepatol 23: 208-214, 2008.

16. Kimura K, Takemoto T. An endoscopic recognition of the atrophic border and its significance in chronic gastritis. Endoscopy 1: 8797, 1969

17. Oken MM, Creech RH, Tormey DC, et al. Toxicity and response criteria of the Eastern Cooperative Oncology Group. Am J Clin Oncol 5: 649-655, 1982.

18. Kanda Y. Investigation of the freely available easy-to-use software 'EZR' for medical statistics. Bone Marrow Transplant 48: 452 458, 2013.
19. Demeester TR, Johnson LF, Joseph GJ, Toscano MS, Hall AW, Skinner DB. Patterns of gastroesophageal reflux in health and disease. Ann Surg 184: 459-470, 1976.

20. Hoppo T, Komatsu Y, Nieponice A, Schrenker J, Jobe BA. Toward an improved understanding of isolated upright reflux: positional effects on the lower esophageal sphincter in patients with symptoms of gastroesophageal reflux. World J Surg 36: 1623-1631, 2012.

21. Cheong JH, Kim GH, Lee BE, et al. Endoscopic grading of gastroesophageal flap valve helps predict proton pump inhibitor response in patients with gastroesophageal reflux disease. Scand J Gastroenterol 46: 789-796, 2011.

22. Xirouchakis E, Kamberoglou D, Kalos D, Zambeli E, Doulgeroglou V, Tzias V. The effect of gastroesophageal flap valve appearance on the management of patients with symptoms of gastroesophageal reflux disease. Dig Dis Sci 54: 328-332, 2009.

23. Chang KC, Wu JF, Hsu WC, Lin BR, Chen HL, Ni YH. Impacts of endoscopic gastroesophageal flap valve grading on pediatric gastroesophageal reflux disease. PLoS One 9: e107954, 2014.

24. Amano K, Adachi K, Katsube T, Watanabe M, Kinoshita Y. Role of hiatus hernia and gastric mucosal atrophy in the development of reflux esophagitis in the elderly. J Gastroenterol Hepatol 16: 132136, 2001.

25. Raghunath A, Hungin AP, Wooff D, Childs S. Prevalence of Helicobacter pylori in patients with gastro-oesophageal reflux disease: systematic review. BMJ 326: 737, 2003.

26. Manes G, Mosca S, Laccetti M, Lioniello M, Balzano A. Helicobacter pylori infection, pattern of gastritis, and symptoms in erosive and nonerosive gastroesophageal reflux disease. Scand J Gastroenterol 34: 658-662, 1999.

27. Hackelsberger A, Schultze V, Günther T, von Arnim U, Manes G, Malfertheiner P. The prevalence of Helicobacter pylori gastritis in patients with reflux oesophagitis: a case-control study. Eur J Gastroenterol Hepatol 10: 465-468, 1998.

28. Shirota T, Kusano M, Kawamura O, Horikoshi T, Mori M, Sekiguchi T. Helicobacter pylori infection correlates with severity of reflux esophagitis: with manometry findings. J Gastroenterol 34: 553-559, 1999.

29. Chiba H, Gunji T, Sato H, et al. A cross-sectional study on the risk factors for erosive esophagitis in young adults. Intern Med 51: 1293-1299, 2012.

30. Hampel H, Abraham NS, El-Serag HB. Meta-analysis: obesity and the risk for gastroesophageal reflux disease and its complications. Ann Intern Med 143: 199-211, 2005.

31. Chung SJ, Kim D, Park MJ, et al. Metabolic syndrome and visceral obesity as risk factors for reflux oesophagitis: a crosssectional case-control study of 7078 Koreans undergoing health check-ups. Gut 57: 1360-1365, 2008.

32. Meining A, Classen M. The role of diet and lifestyle measures in the pathogenesis and treatment of gastroesophageal reflux disease. Am J Gastroenterol 95: 2692-2697, 2000.

33. El-Serag HB, Johanson JF. Risk factors for the severity of erosive esophagitis in Helicobacter pylori-negative patients with gastroesophageal reflux disease. Scand J Gastroenterol 37: 899-904, 2002.

34. Mohammed I, Cherkas LF, Riley SA, Spector TD, Trudgill NJ. Genetic influences in gastro-oesophageal reflux disease: a twin study. Gut 52: 1085-1089, 2003.

35. Dennish GW, Castell DO. Inhibitory effect of smoking on the lower esophageal sphincter. N Engl J Med 284: 1136-1137, 1971.

36. Trudgill NJ, Smith LF, Kershaw J, Riley SA. Impact of smoking cessation on salivary function in healthy volunteers. Scand J Gastroenterol 33: 568-571, 1998.

37. Akiyama $\mathrm{T}$, Inamori $\mathrm{M}$, Iida $\mathrm{H}$, et al. Alcohol consumption is associated with an increased risk of erosive esophagitis and Barrett's epithelium in Japanese men. BMC Gastroenterol 8: 58, 2008. 
38. Kaufman SE, Kaye MD. Induction of gastro-oesophageal reflux by alcohol. Gut 19: 336-338, 1978.

39. Keshavarzian A, Polepalle C, Iber FL, Durkin M. Esophageal motor disorder in alcoholics: result of alcoholism or withdrawal?. Alcohol Clin Exp Res 14: 561-567, 1990.

40. Zhang ZF, Kurtz RC, Yu GP, et al. Adenocarcinomas of the esophagus and gastric cardia: the role of diet. Nutr Cancer 27 298-309, 1997

41. Terry $P$, Lagergren J, Ye W, Nyrén O, Wolk A. Antioxidants and cancers of the esophagus and gastric cardia. Int J Cancer 87: 750754, 2000.

42. Mayne ST, Risch HA, Dubrow R, et al. Nutrient intake and risk of subtypes of esophageal and gastric cancer. Cancer Epidemiol
Biomarkers Prev 10: 1055-1062, 2001.

43. Zhang ZF, Kurtz RC, Sun M, et al. Adenocarcinomas of the esophagus and gastric cardia: medical conditions, tobacco, alcohol, and socioeconomic factors. Cancer Epidemiol Biomarkers Prev 5: 761-768, 1996

44. Gammon MD, Schoenberg JB, Ahsan H, et al. Tobacco, alcohol, and socioeconomic status and adenocarcinomas of the esophagus and gastric cardia. J Natl Cancer Inst 89: 1277-1284, 1997.

The Internal Medicine is an Open Access article distributed under the Creative Commons Attribution-NonCommercial-NoDerivatives 4.0 International License. To view the details of this license, please visit (https://creativecommons.org/licenses/ by-nc-nd/4.0/).

(C) 2017 The Japanese Society of Internal Medicine http://www.naika.or.jp/imonline/index.html 